Article

\title{
Evaluation Methodology for Tariff Design under Escalating Penetrations of Distributed Energy Resources
}

\author{
Ibtihal Abdelmotteleb ${ }^{1,2,3, *}$, Tomás Gómez ${ }^{1}$ and Javier Reneses ${ }^{1}$ \\ 1 Institute for Research in Technology, Comillas Pontifical University, Madrid 28015, Spain; \\ tomas.gomez@comillas.edu (T.G.); javier.reneses@comillas.edu (J.R.) \\ 2 Faculty of Technology, Policy and Management, Delft University of Technology, Delft 2628, The Netherlands \\ 3 Faculty of Electrical and Control Engineering, Arab Academy for Science, Technology and \\ Maritime Transport, Cairo 11361, Egypt \\ * Correspondence: iabdelmotteleb@comillas.edu or i.i.a.abdelmotteleb@tudelft.nl
}

Academic Editor: Peter V. Schaeffer

Received: 22 March 2017; Accepted: 1 June 2017; Published: 5 June 2017

\begin{abstract}
As the penetration of distributed energy resources (DERs) escalates in distribution networks, new network tariffs are needed to cope with this new situation. These tariffs should allocate network costs to users, promoting an efficient use of the distribution network. This paper proposes a methodology to evaluate and compare network tariff designs. Four design attributes are proposed for this aim: (i) network cost recovery; (ii) deferral of network reinforcements; (iii) efficient consumer response; (iv) recognition of side-effects on consumers. Through an analytical hierarchy process (AHP), the evaluation methodology is applied to compare traditional cost allocation methods, on the basis of $100 \%$ energy, $100 \%$ demand, and $50 \%$ energy-50\% demand, with more advanced pricing methods based on distribution locational marginal prices in combination with cost-reflective network charges. Numerical results are obtained through a case study based on the IEEE 34-node test feeder with DER integration. The results illustrate the advantage of advanced pricing methods to promote an efficient integration of DER and demand price-response from consumers.
\end{abstract}

Keywords: analytical hierarchy process; distributed energy resources; distribution locational marginal prices; distribution network tariff; peak-coincidence network charges

\section{Introduction}

Distribution networks are gradually suffering a transformation as the penetration level of distributed energy resources (DERs) escalates, requiring modifications in a number of related issues. One of those issues is revisiting distribution tariff designs. The distribution network has recently been facing new concerns due to DERs integration that traditionally were not undertaken, such as bi-directional flows and increasing stranded costs. Previously, the electricity flows travelled from generation through transmission and down to distribution. Nowadays, with the increasing deployment of DERs, some flows are in the opposite direction, flowing up from distribution to transmission grids. Besides, DERs are serving for self-consumption, reducing the usage of the network, and increasing the stranded costs. However, DERs are also beneficial, as they are capable of reducing costs by postponing reinforcements, reducing losses, and most of them are environmentally friendly.

Distribution system operators (DSOs) seek to manage distribution networks optimally, in the sense of maintaining the network's security at minimum possible cost. Their target is associated to improving reliability and efficiency of real-time operation and future planning. Nowadays, a greater number of microgrids are being developed that are composed of different DERs such as on-site 
distributed generators (DGs), which may include microturbine generators (MTGs), battery energy storage systems (BESSs), photovoltaic cells (PV), diesel engines, wind energy conversion systems, fuel cells, and electric vehicles (EV) [1]. A microgrid is considered a localized grid that can operate in grid-connected mode or autonomously. It may increase the network's reliability, as well, it may raise network security and stability issues, such as network faults and voltage deviations. An efficient way to detect such problems, could be through accommodating fault analysis programs, as proposed and discussed in [1,2]. Network problems could be avoided or resolved in a number of approaches, one of which is to reinforce the network. Another approach is to use DERs to resolve network problems, such as coordinating EV charging stations to improve voltage deviations [3]. Moreover, hybrid systems consisting of different types of DERs, may also act as an efficient approach to maintain network stability as they may perform complementarily to each other. In addition, they may offer further benefits with maximum power point tracking (MPPT) consideration, as introduced for both PV and wind in [4]. Thus, DERs may provide many opportunities to DSOs, but a communication gap remains between them. DSOs need to transmit signals to DERs to modify their consumption/generation portfolio, which could be accomplished through an efficient tariff design that addresses the current and future needs on the network. The distribution tariff is required to guide the consumers through economic signals to efficiently use the network, promoting the beneficial aspects provided by DERs while mitigating negative impacts.

Numerous tariff methodologies could be designed and implemented. Many researches proposed and discussed different approaches to design distribution network tariffs by allocating distribution network costs to consumers using different criteria. Postage stamp (PS) and contract path are non-flow based methods that are used due to their simplicity [5]. Whereas, MW-Mile and MW-MVar methods are based on the magnitude, the path and the distance traveled by the transacted power between the points of injection and withdrawal [6]. MW-Amp is another very similar method based on marginal changes in current, as opposed to power [7]. Moreover, marginal participation (MP) method allocates the cost of a line on the basis of the marginal impact that a network user has on the line flow. It is a flow based method that uses marginal participation sensitivity of a line (also called power transfer distribution factor, PTDF) [8-10]. Average participation methods, also known as Bialek's and Kirschen's power tracing methods, rely on the use of proportional sharing of flows into and out of any node [11]. Moreover, there are methods based on long-term marginal costs (LTMC) pricing, which uses analytical equations to evaluate the impact of nodal injection on long-run network development costs $[12,13]$, and long-term incremental cost (LTIC) pricing, which uses a traditional system planning approach to determine the required reinforcements and the corresponding investment schedules with and without each transaction [14,15]. On the other hand, short-term marginal costs (STMCs), also known as locational marginal pricing (LMP), is an energy pricing method based on the marginal cost of accommodating a marginal increase in the transacted power [16-18]. It is used to price energy at each node, and its surplus is used to recover part of the network costs. In [19], the authors illustrated the benefits gained through the implementation of LMPs in the distribution level.

Several authors had combined methods together as they act complementarily to each other while providing more merits. In [20], the authors combined LMPs with MW-Mile. The method seems promising as it introduces LMPs within the distribution network; however, the MW-Mile is not suitable for distribution networks as it is only applicable to bilateral transactions where the points of injection and reception are known, which is difficult to apply with disperse deployment of DERs. The authors of [21] proposed a cost-reflective method based on allocating the incremental costs associated with network cost drivers to consumers using weighted average computed through consumers' contribution to cost drivers. This approach is a blend of an incremental and average cost approach. The approach relies upon the use of a reference network model (RNM) to identify the key drivers of distribution system costs and then the allocation of those costs according to network utilization profiles that capture each consumer's contribution to and share of total system costs. Another similar approach that also uses RNM is presented in [22], but without considering DERs. The method is divided into three steps: 
the definition of a tariff structure, the allocation of total costs to each cell of the tariff structure, and the computation of the final rates.

There are two related aspects when discussing tariff designs: the basis upon which costs are allocated to consumers and the form it is presented in. There are basically three forms of tariff charges that are selected from or combined to present the end-user prices: demand (capacity) charges, energy (volumetric) charges, and fixed charges. Fixed charges are not a function of the consumer's consumption during the billing period, they are fixed payments per consumer that are done regularly on different temporal bases (monthly, semi-annually, annually, etc.). They are set to cover certain expenses without any intention to incentivize the consumers to alter their consumption. Whereas, traditional energy and demand charges are based on the consumption done within the billing period, on the basis of $\mathrm{kWh}$ and $\mathrm{kW}$ respectively, for which they may have different tariff structures: single priced (flat tariffs), time-of-use (TOU), critical-peak pricing (CPP), and capacity-based [23-27]. Energy and demand charges are more concerned with incentivizing the consumers to change their consumption habits with time-differentiated prices. Traditional tariffs follow ex-ante procedures, where consumers are informed prior the tariff period with all the information they need to anticipate their payments and, thus, they react to that given information. The price of each $\mathrm{kWh}$ and $\mathrm{kW}$ is announced, and if time-differentiated prices are used, the costs and their accompanying periods are known in advance.

Tariff designs could strongly affect and influence consumers' responses and the system's economic efficiency. For example, in [28], the authors discussed how the tariff design affects the short-term and long-term decisions of a consumer through a PV-coupled battery system. Each of the tariff designs holds certain pros and cons. On what basis should a tariff be evaluated? What criteria should be used to promote a tariff design over the other? Some kinds of benchmarks are required to refer to in order to assess tariff designs. This issue has not been widely addressed in previous research. In [15], the authors presented a framework for assessing the economic efficiency of different long-term network pricing models. Each model is assessed in terms of the investments needed in the network to meet the requirements of the load and generation within its methodology. The presented approach assessed the response of new and existing consumers to pricing signals by comparing the different pricing methodologies to find the most effective at encouraging the economic development of the distribution network, particularly in the sense of increasing distributed generation. The three pricing models that were considered were postage stamp, MW + MVar-Miles and long-run incremental cost pricing (LRIC). The applied framework demonstrated the differences in future network investment cost driven by each price model. Moreover, in [29] the authors proposed a tariff efficiency measure that is divided into two aspects in order to measure the cost reflectivity of a tariff. The first aspect is related to the minimization of the costs of the grid in the future and the costs of the reaction while meeting the demand. The other aspect is related to the reflective allocation of the costs for the existing grid. A third aspect that was less focused on was the profitability of the business case of local generation. The paper addressed how to measure those aspects, given the consumers' reaction. Both mentioned papers focused on measuring to which extent the applied tariff design was capable of reducing future network costs through different approaches. Yet, there are other aspects that should also be considered when assessing tariff designs, as in [30], where the authors discussed different attributes including economic efficiency, revenue adequacy, simplicity, and prevention of cross-subsidization.

This paper proposes an evaluation methodology to assess the performance of different tariff designs. It is based on four design attributes: (i) network cost recovery; (ii) deferral of network reinforcements; (iii) efficient consumer response; and (iv) recognition of side-effects on consumers. Analytical hierarchy process (AHP) is then used to evaluate each of the candidate tariff designs according to their performance in each of the four attributes. Furthermore, the proposed evaluation methodology is applied onto two tariff designs: one is based on traditional cost allocation approaches and the other is based on a cost-reflective approach as proposed in [31] which consists of two complementary parts. First, DLMPs (distribution locational marginal prices) are used to price energy 
at each node, and its surplus is used to recover part of the network costs. Then, the remaining cost of the network is allocated to the consumers using peak-coincident network charges (PCNC).

This paper is organized as follow: Section 2 discusses the implemented cost-reflective distribution tariffs, Section 3 presents the proposed evaluation methodology, Section 4 presents the case studies and the results obtained, and finally, Section 5 draws the final conclusions.

\section{Cost-Reflective Tariff Design}

Cost-reflective tariffs are promising in the way that they reflect the actual costs incurred by each consumer/generator. They are seen as a means of ensuring greater social equity by reducing the largely invisible cross-subsidies embodied in flat-rate tariffs [32]. However, there are arguments and doubts whether cost-reflective pricing would yield desired outcomes. Hence, this paper aims to apply the proposed evaluation methodology to evaluate and compare cost-reflective tariff designs to traditional ones. A cost-reflective method that the authors proposed in [25] is assessed through the proposed evaluation methodology. The cost-reflective tariff design implemented in this paper is one variant of that presented in [31], which is another approach of combining network cost allocation methods together to achieve the desired distribution tariff outcomes. Since consumers do not react to network tariffs solely, but to the retail price as a whole, and particularly to the energy prices, it is sensible to integrate both energy prices and distribution network tariffs when designing tariffs. Within the implemented tariff design, first, DLMPs are used to price energy consumption/injection at each node. Then, a surplus is earned through DLMPs that is assigned to recover part of the network cost, while the remaining network costs is recovered through PCNC.

DLMPs are computed through optimal power flow (OPF), which aims to maximize the social welfare. The objective function presented in (1) maximizes the difference of consumer benefit and the total cost of active and reactive power generation, where $\mathrm{G}$ is the generator set, $\mathrm{D}$ is the consumer set, $\mathrm{C}_{\mathrm{pi}}\left(\mathrm{P}_{\mathrm{gi}}\right)$ is the active power production cost of generator $\mathrm{i}, \mathrm{C}_{\mathrm{qi}}\left(\mathrm{Q}_{\mathrm{gi}}\right)$ is the reactive power production cost of generator $\mathrm{i} ; \mathrm{B}_{\mathrm{i}}\left(\mathrm{P}_{\mathrm{di}}\right)$ is the benefit of the consumer, $\mathrm{P}_{\mathrm{gi}}$ and $\mathrm{Q}_{\mathrm{gi}}$ are the active and reactive power output of the generator on bus $\mathrm{i}, \mathrm{P}_{\mathrm{di}}$ is the active power demand on bus i [33]. This is subject to network constraints expressed (2)-(5). Equations (2) and (3) present power flow equations, which is a set of equations that characterizes the flow of real and reactive powers through a system, where $\mathrm{N}$ is total number of buses in the system, $V_{i}$ and $V_{j}$ are the magnitudes of the voltages of bus $i$ and $j$, respectively, $\delta_{\mathrm{i}}$ and $\delta_{\mathrm{j}}$ are the voltage angles of bus $\mathrm{i}$ and $\mathrm{j}$, respectively, and $\mathrm{Y}_{\mathrm{ij}}$ and $\theta_{\mathrm{ij}}$, are the magnitude and angle of $\mathrm{ij}^{\text {th }}$ element of the bus admittance matrix, for each hour $\mathrm{t}$ [33]. Line limits expressed in (4) refer to $S_{1}^{\max }$ which is the maximum apparent power that could be transmitted through line 1 , and $S_{1, t}$ is the apparent power flowing through line 1 at time $t$. The voltage at each bus should be within the specified range as in (5).

$$
\begin{gathered}
\max \left[\sum_{i \in D} B_{i}\left(P_{d i}\right)-\sum_{i \in G} C_{p i}\left(P_{g i}\right)-\sum_{i \in G} C_{q i}\left(Q_{g i}\right)\right] \\
P_{g i, t}-P_{d i, t}=\sum_{j=1}^{N} V_{i, t} V_{j, t} Y_{i j} \cos \left(\delta_{i, t}-\delta_{j, t}-\theta_{i j}\right) \\
Q_{g i, t}-Q_{d i, t}=\sum_{j=1}^{N} V_{i, t} V_{j, t} Y_{i j} \sin \left(\delta_{i, t}-\delta_{j, t}-\theta_{i j}\right) \\
S_{l, t} \leq S_{l}^{\max } \\
V_{i}^{\min } \leq V_{i, t} \leq V_{i}^{\max }
\end{gathered}
$$

DLMPs are the shadow prices of the real power balance equality constraints in (2). They send economic short-term signals using efficient energy prices. Thus, they enhance market trading through optimal operation and dispatch of resources. A surplus is obtained as presented in (6) through the 
difference between load payments at each node $\mathrm{DLMP}_{\mathrm{i}} \times \mathrm{P}_{\mathrm{di}}$ and generator market revenues at each node DLMP $\times \mathrm{P}_{\mathrm{gi}}$. This surplus is used to recover total network costs (TNC), although typically it will be only a small portion of them as shown in (7) for the case of transmission networks. Whereas the remaining network costs (RNC), which are the majority of the total cost, are recovered through network charges that are allocated to network users using PCNC. PCNC allocates costs to consumers in $€ / \mathrm{kW}$ according to their contribution to the feeder's stress hour(s), which may be due to consumption or injection as in (8). This aims to guide the consumers through their long-term decisions, affecting DER investment choices while ensuring the recovery of the network costs. Equation (8) is based on the number of stressful hours considered. If there is more than one stressful hour, then the part for RNC will be allocated to each of these hours along with the corresponding total power consumed in the case of a peak due to demand, or total power injected in the case of a peak due to generation.

$$
\begin{gathered}
\text { DLMP Surplus }=\sum_{i \in \mathrm{D}} \mathrm{DLMP}_{\mathrm{i}} \times \mathrm{P}_{\mathrm{di}}-\sum_{\mathrm{i} \in \mathrm{G}} \mathrm{DLMP}_{\mathrm{i}} \times \mathrm{P}_{\mathrm{gi}} \\
\mathrm{RNC}=\mathrm{TNC}-\text { DLMP Surplus } \\
\mathrm{PCNC}_{\mathrm{t}}=\frac{\mathrm{RNC}_{\mathrm{t}}}{\sum_{\mathrm{i} \in \mathrm{D}} \mathrm{P}_{\mathrm{di}, \mathrm{t}}}
\end{gathered}
$$

Another important aspect of tariff design is the information to be passed onto consumers, which includes two parts: the tariff and its accompanying period. Whether the information should be announced ex-ante or ex-post affects widely the reaction of the consumers, and also the recovery of network costs. In this cost-reflective tariff, the information is provided through three phases, as illustrated in Figure 1: ex-ante, real time-operation, and ex-post. In ex-ante, the hourly day ahead DLMPs and the expected (according to forecasts) network stress hour(s) are announced. This information is subject to change closer and during real time operation, when the actual generation and demand values are known. Then, ex-post, network charges are allocated according to the actual stress hour(s) of the elapsed period, which may or may not concur with the information provided ex-ante. According to the actual stress hours of the network, PCNC is allocated. In order to increase the certainty of the actual stress hours of the network, consumers are communicated with regularly and especially closer to real-time to warn and guide their behavior. Other methods could be used as integrating aggregators between DSOs and consumers to facilitate communication between them and lead to more accurate information transmitted in both directions.

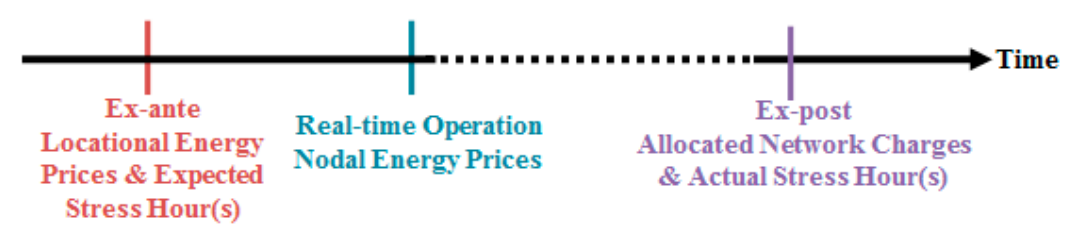

Figure 1. Cost-reflective method's information notification time-line.

\section{Evaluation of Tariff Designs}

The distribution network tariff is a part of the total price received by the consumer. Other parts include generation, transmission, retailing costs, policy costs, and taxes. This evaluation methodology considers the energy prices along with the distribution tariffs that are determined by regulators and implemented for a certain period of time, within which various consumer reactions to the implemented tariff and energy prices are generated. Figure 2 illustrates the energy reaction cycle, starting at stage one when the method is implemented. Then, as a consequence, in the second stage consumers react to energy prices and network charges. Those signals guide the consumers through operational decisions in which they would modify their consumption/injection patterns. Some consumers could further react taking long-term DER investment decisions as shown in the third stage, or as in the fourth stage, 
consumers may be incentivized to participate in providing price-response demand services. Thus, based on prices and consumers' reaction to it, payments are allocated. In the fifth stage the money is collected, where the part associated with energy prices is traded in the market and the remaining is assigned to recover the network costs. Finally, in the sixth stage, adjustments to the network tariff are made by the regulator to adapt it to the network's new circumstances to ensure the recovery of the network costs in the following period.

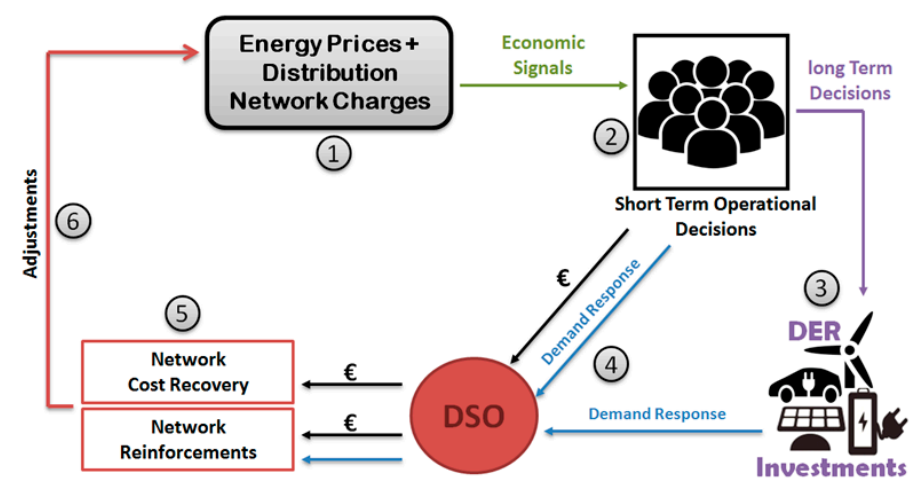

Figure 2. Tariff design reaction cycle. DER = distributed energy resource.

Distribution tariffs should be designed to fulfill three main objectives: firstly, to fully recover the distribution network costs, secondly to defer or mitigate, if possible, network reinforcements, and thirdly to allocate the network costs to consumers following economic efficiency principles. The third objective is a very critical issue, since the payments allocated to each consumer will be an influential tool used to guide their behavior towards the network. It is crucial to ensure that correct signals are received by all consumers through those payments. Incorrect signals may result in poor consumers' responses, undesired reduction in their network usage or, in extreme cases, network disconnection. Thus, costs should be assigned to each consumer based on their impact on the network. In other words, those having positive impacts on the network (such as reduction in losses or mitigating network reinforcements) will be rewarded or otherwise penalized. A way to measure the performance of a tariff design is required, in order to evaluate, compare and capture the points of strength and weakness of each design. It is assumed that consumers have economic rational behavior, as they make decisions that result in the most optimal benefit for them given a set of constraints. The outcomes to be assessed are referred to as attributes in this paper. There are four proposed attributes to be assessed as illustrated in Figure 3, which we consider as the most relevant for comparing tariff designs for active consumers, in addition to the main regulatory tariff principles such as simplicity, stability, equity, consistency, efficiency, transparency, etc. [34].

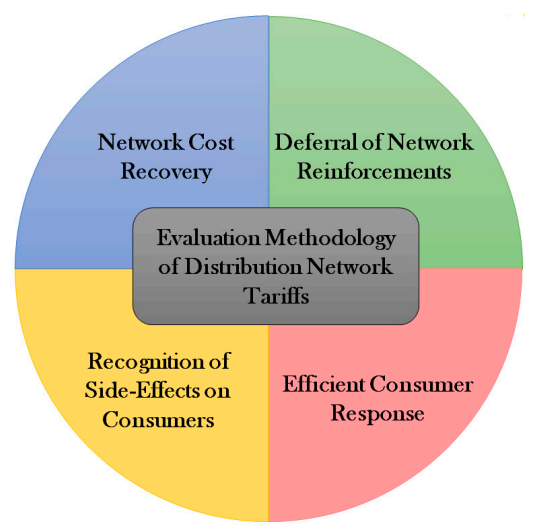

Figure 3. Evaluation methodology attributes. 


\subsection{Tariff Design Attributes}

\subsubsection{Network Cost Recovery}

The tariff is expected to recover the distribution network costs. If tariffs are predefined ex-ante, prior to its period of application, it cannot ensure full cost recovery. Thus, it is expected that the total amount collected through consumers' payments would depart from the allowed amount. The issue of unrecovered network costs is to be of concern if a considerable difference is detected, resulting in a major deficit or surplus. Deficits would be due to consumers who had reduced their network usage, while surpluses would be due to those who increased it. This deficit is then transferred to the following period, to be included in the readjusted tariff. When comparing tariff designs, this attribute aims to find which of them ensures network cost recovery.

\subsubsection{Deferral of Network Reinforcements}

Network reinforcements are postponed, unless no other alternative approach is available. Therefore, consumers need to be advised prior to making reinforcement decisions. The tariff design should be able to capture the reinforcements needed in a network and alert those consumers potentially responsible for it through economic signals. Either they react to the signal, reducing their impact, or do not react and are assigned the reinforcement costs. When comparing tariff designs, this attribute aims to find which of them is capable of signaling the need of network reinforcements. Tariffs that consider the utilization level of the network are likely to perform better in this attribute.

\subsubsection{Efficient Consumer Response}

Consumer response could be achieved in different ways and over different time horizons. Short-term consumer response considers the change in the consumption/injection profile of consumers responding to dynamic prices (price-response). Thus, the tariff design should encourage consumers to react to prices in order to optimize the use of the network. Tariff designs that price energy dynamically instead of flat rates, and allocate network charges targeting critical hours of the network, are more consumer response motivating.

Furthermore, consumer response could be extended to long-term decisions, as investing in DERs. Consumers need to be well guided through investment decisions, as incorrect signals received by consumers, may lead to inefficient DER investment decisions adopted by them. From the consumers' perspective, they will rationally invest in DERs if they benefit, i.e., if their payments would be reduced. From the system's perspective, consumers' DER investments would reduce system costs, or otherwise it would increase the stranded costs. Thus, consumers should be well guided to invest in DERs only when it would enhance the system's economic efficiency. When comparing tariff designs, this attribute aims to asses which design is able to or has a higher potential to encourage consumers to modify their profile pattern efficiently and reduce system costs, while is also capable of correctly influencing network user's DER investment decisions.

\subsubsection{Recognition of Side Effects on Consumers}

For any tariff design, several side effects could be generated, mainly due to cross-subsidization and fairness issues, requiring certain trade-offs to be considered. Within tariff design, the main trade-off is between efficiency and fairness, particularly regarding customer cost allocation that should avoid undue discrimination. Fairness issues are tackled through a number of issues, such as the location factor. Should consumers located away from the generation be penalized with more payments? Or is it fair in order to promote efficient cost allocation? To which degree is the fairness goal more important in matters of regulatory process or more important in regulatory outcomes, is a question that commissioners' response varied to widely according to a survey carried out in [35]. Other side-effects could be through avoiding network charges causing cross-subsidization. As active network users invest in DERs and become prosumers, this affects their payments as well as it may affect the rest of 
the consumers' payments, depending on the tariff design. A well-designed tariff will generate positive side-effects on the rest of the consumers when DER investments have been done in a context of system efficiency, reducing their payments or at least maintaining them. Whereas, a poorly designed tariff would generate negative side-effects on consumers, allocating to them higher payments in following tariff periods. When comparing tariff designs, this attribute aims to find which is more effectively able to recognize those side effects.

\subsection{Analytical Hierarchy Process (AHP)}

The AHP decision-making method is proposed to quantitatively compare different tariff designs. AHP attempts to determine the relative importance, or weight, of the considered tariff designs in terms of each attribute using pairwise comparisons [36]. It is used for solving different types of multi-criterion decision problems based on the relative priorities assigned to each criterion's role in achieving the stated objective. Using a benefit measurement (scoring) model that relies on subjective managerial inputs on multiple criteria, these inputs are converted into scores that are used to evaluate each of the possible alternatives [37]. Figure 4 illustrates the hierarchy levels of the decision-making problem. First level presents the problem's objective, followed by the second level presenting the criteria (attributes), and finally, the third level presents the alternatives (tariff design options). Prior to the decision being made, the regulator should decide on the priority each attribute has over the other. Then, using a scale of numbers (1-9), each tariff design is compared with the other, indicating how many times more important or dominant one is over the other with respect to each attribute.

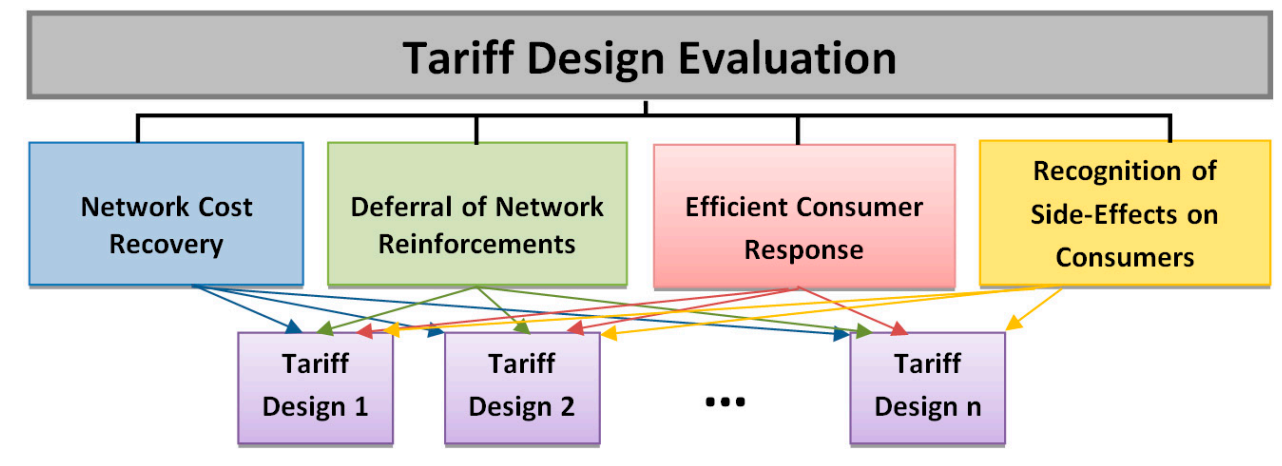

Figure 4. Tariff design evaluation using analytical hierarchy process (AHP).

\section{Case Study and Results}

Case studies were executed to compare between the traditional and the cost-reflective tariff designs. Each tariff design was evaluated according to the proposed methodology. All case studies were carried out on the distribution network of the IEEE 34 Node Test Feeder, an actual feeder located in Arizona, illustrated in Figure 5 and explained in [31]. The network (feeder) was modeled using a modified version of Matpower [38] that includes voltage regulator (VR) controls, and according to network details available in $[39,40]$. The network is connected to the upper grid (Grid) which symbolizes the generation and transmission network, upon which nodal prices are calculated and presented to the distribution network. Hourly day ahead prices used are extracted from the Spanish electricity market OMIE (Operador del Mercado Ibérico Español) data, which manages the spot market in the Iberian Peninsula [41]. It is assumed that at each node, a number of consumers are grouped together, and the profile of each consumer is generated using a load profile generator software [42]. 


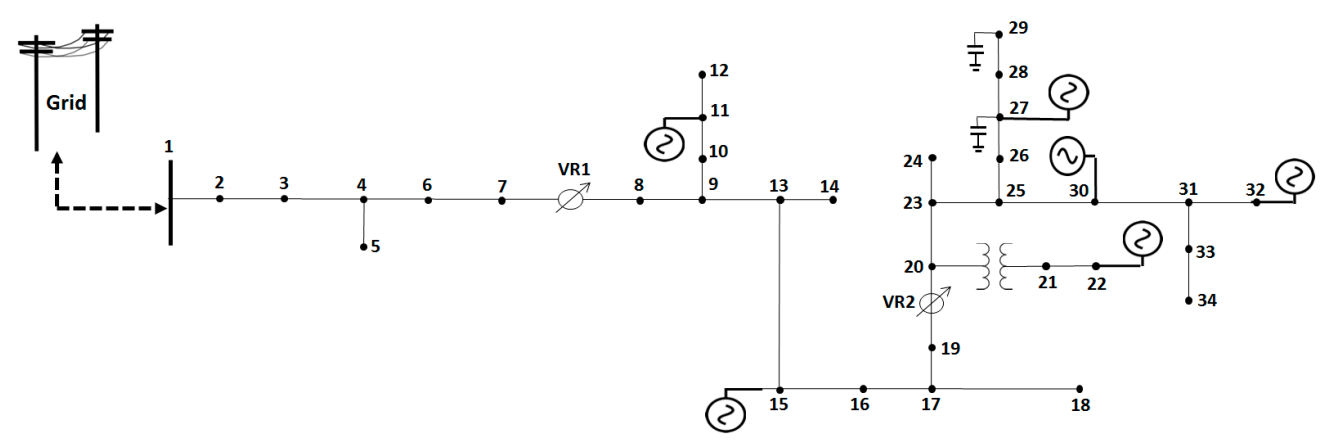

Figure 5. IEEE 34 node test feeder.

Although tariff periods usually last a year or longer, the simulation period considered for this case study is one day, corresponding to a peak day for the network. Peak hours are critical periods of the network, where managing the network's operation could be challenging for the DSO. DERs and demand response may have positive impacts, subject to the tariff design implemented. Thus, the scope of one peak day is implemented to analyze the payments assigned to consumers within each tariff design. The scope of this paper does not consider seasonal variations between demand and PV generation along the year, which could be considered with potential different situations of maximum utilization of the network. The total cost of the distribution network for the considered day is $€ 943.66$. It is calculated based on the cost of all assets within the network according to the RNM (reference network models) library, which is a computational tool for planning and designing large-scale smart distribution networks [43].

Within each tariff design, traditional and cost-reflective, several case studies were carried out. First, with no DER integration, and then DERs were added to the network in the form of PV generators. Five PV generators were added, as shown in Figure 5, each with an installed capacity equivalent to the maximum consumption of the node it is connected to. The total PV installation in the network is $1 \mathrm{MW}$ corresponding to $64 \%$ of the network's peak load, and producing $6.13 \mathrm{MWh}$ per day which corresponds to $28 \%$ of the network's energy consumption. The grid is the main source of generation in this network and considered the only available generation during the cases of no DER integration. With DER integration, PV generators having zero variable cost are dispatched first. Figure 6 presents the total load, the PV production and the net load over the implementation period. As shown in the figure, the main hours of PV production fall between 10:00 and 16:00, with peak production at 13:00.

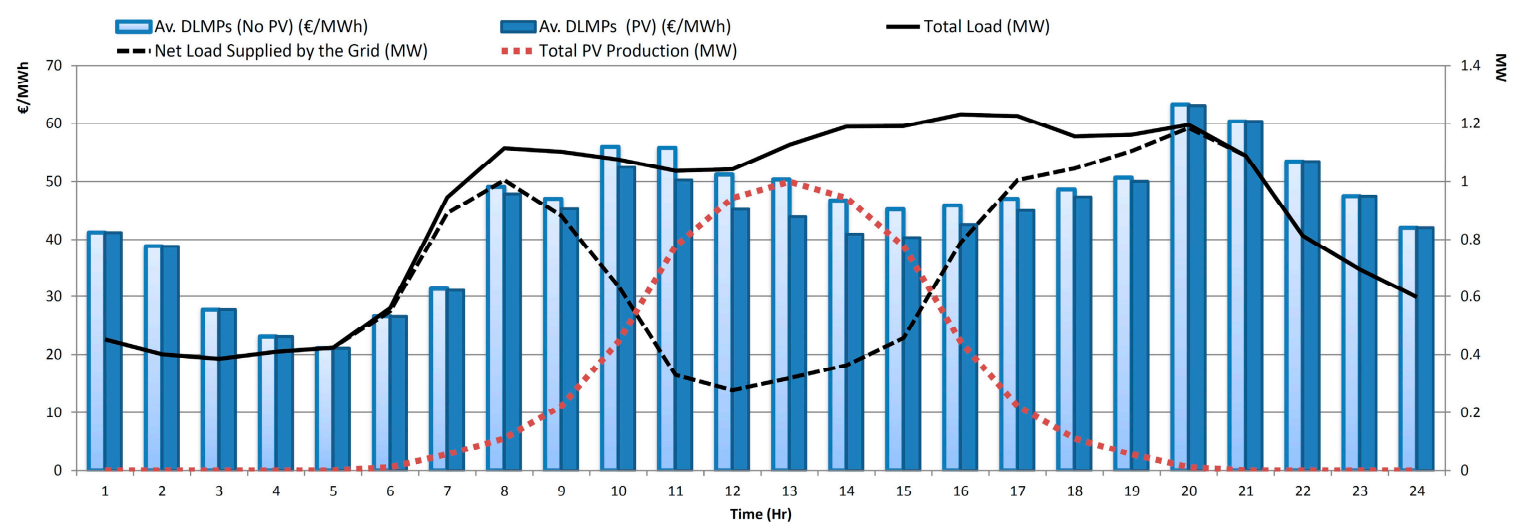

Figure 6. Total load, net load supplied by the grid, photovoltaic cells (PV) production and average DLMPs during the implementation period.

The integration of PV led to a number of variations in the network. First, it reduced the losses within the network by $46 \%$, due to a reduction in the amount of energy acquired by the upper grid. 
In addition, the PV reduced the DLMPs in the hours of its generation as shown in Figure 6. It also shifted the hour of peak load from 16:00 to 20:00. Figure 7 shows how the DLMPs changed across the feeder and with and without PV.

For the traditional tariff design, three case studies were implemented: the first case was based on energy charges (100\% energy), the second was based on demand charges (100\% demand), and the third was based on $50 \%$ energy-50\% demand. In all three cases, a flat energy charge was set to $39.40 € / \mathrm{MWh}$. Network charges were calculated for each case to recover the network costs based on no PV integration. It was set to $43.65 € / \mathrm{MWh}$ for the first case where it is based solely on the energy consumption, $601.63 € / \mathrm{MW}$ for the second case where it is based solely on the individual peak demand consumption, and half each of those values for the third case (21.82 $€$ /MWh and $300.82 € / \mathrm{MW})$ where half of the network costs are recovered through energy consumption and the other half through demand. Figure 8 compares the payments per consumer for the first case.

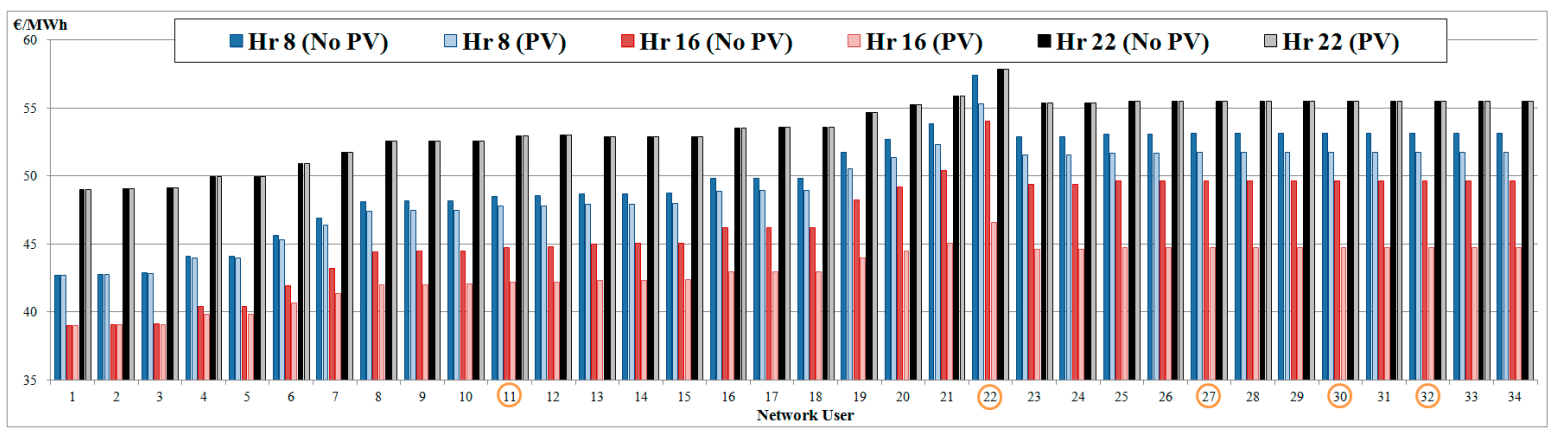

Figure 7. Comparing DLMPs during different hours with and without PV integration.

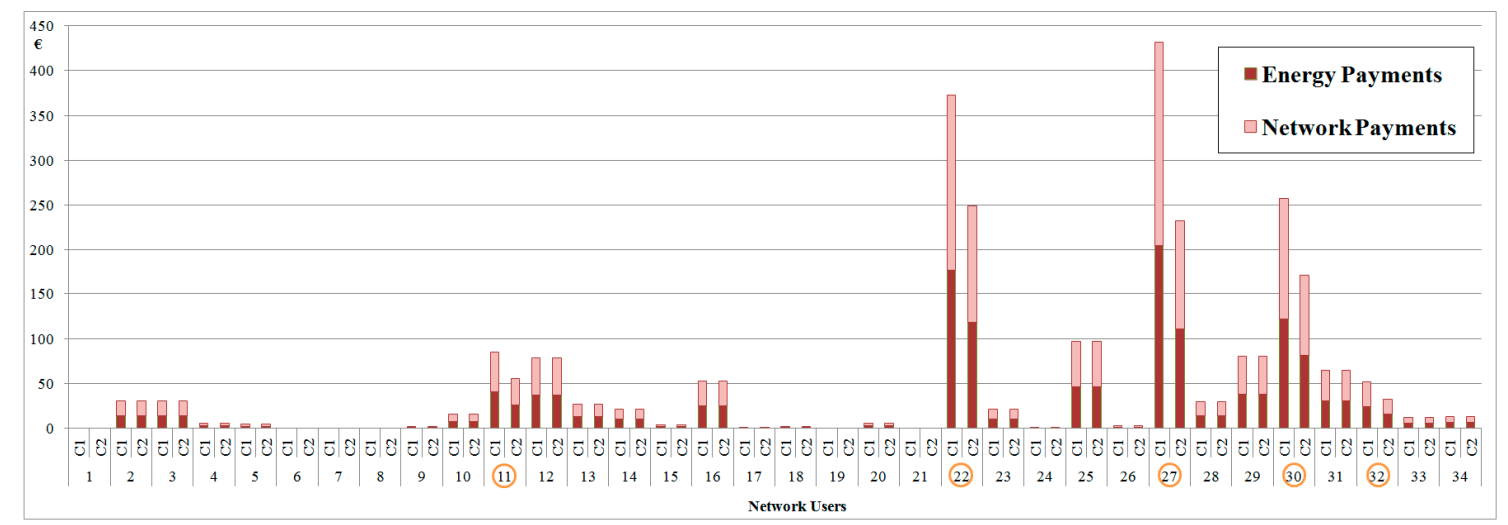

Figure 8. Traditional tariff design case 1 based on 100\% energy: change in payments of 1 day due to PV integration. $\mathrm{C} 1=$ no PV case, $\mathrm{C} 2=\mathrm{PV}$ case.

For the cost-reflective tariff design, DLMP payments were allocated to consumers along with PCNCs. PCNCs were allocated based on their contribution to the feeder's peak hour, which changed from 16:00 to 20:00 with the integration of PV. Figure 9 illustrates the payments per consumer under cost-reflective tariff deign with and without PV. 


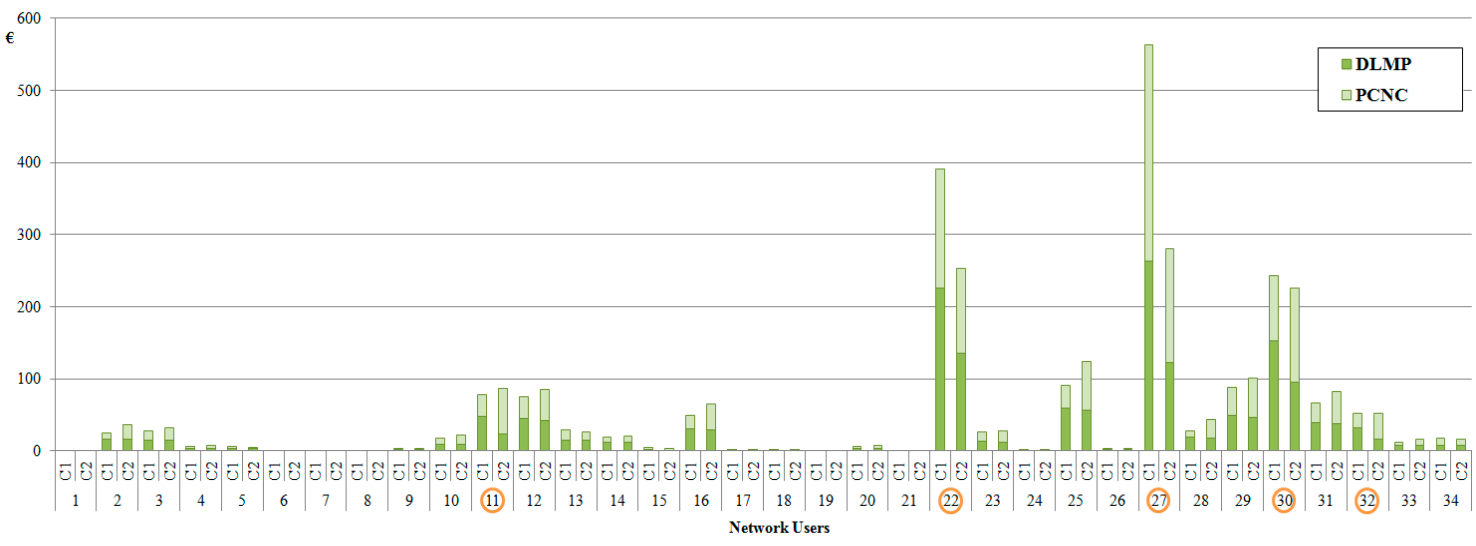

Figure 9. Cost-reflective tariff design: change in payments due to PV integration. $\mathrm{C} 1=$ no PV case, $\mathrm{C} 2=\mathrm{PV}$ case.

\subsection{Tariff Design Attributes Evaluation}

\subsubsection{Network Cost Recovery}

For the traditional tariff design, the three case studies led to different degrees of cost recovery. Table 1 presents the results obtained by the three case studies regarding cost recovery with and without PV. It shows that full cost recovery is obtained with no PV. However, due to PV integration, a major reduction was observed with the energy payments and a minor one in the demand payments. Thus, the use of volumetric tariffs leads to a greater deficit than that of demand tariffs. These deficits are to be included in the following period tariffs. On the contrary, the cost-reflective method provides part of the tariff ex-ante to guide the consumers through their short-term decisions as they plan their injection/consumption profiles, while the rest of the tariff is ex-post to ensure the full recovery of the network costs.

Table 1. Network cost recovery under traditional tariff designs.

\begin{tabular}{lcc}
\hline \multirow{2}{*}{ Cost Allocation Basis } & \multicolumn{2}{c}{ Total Cost Recovered (€) } \\
\cline { 2 - 3 } & No PV & PV \\
\hline 100\% Energy & 943.66 & 702.74 \\
100\% Demand & 943.66 & 848.14 \\
50\% Energy-50\% Capacity & 943.66 & 775.44 \\
\hline
\end{tabular}

\subsubsection{Deferral of Network Reinforcements}

Network reinforcements are linked to the network's peak hours, which is the main aspect to consider when comparing tariffs in this attribute. One hundred percent energy tariff design does not consider this aspect, as it is purely based on energy consumption. Thus, as shown in Figure 8, consumers with no PV do not receive any changes in their payments, while prosumers, those invested in PV (consumers 11, 22, 27, 30, and 32) were able to reduce their payments. For the $100 \%$ demand tariff, it is based on individual peaks, which does not particularly coincide with network peaks. Thus, consumer payments do not reflect the network's status or needs. The performance of the $50 \%-50 \%$ tariff falls between the two mentioned tariff designs.

As for the cost-reflective method, PCNC payments, which are based on network peaks, clearly signalize consumers regarding their contribution to the network as shown in Figure 9. In Figure 10. The contribution to the network's peak hour with and without PV integration (hours 20 and 16, respectively) is compared for prosumers 27 and 30 . The contribution of prosumer 27 to the peak was 
reduced, and prosumer 30 was increased. This is reflected in their PCNC payments in Figure 9, and not in the network payments under 100\% energy in Figure 8.

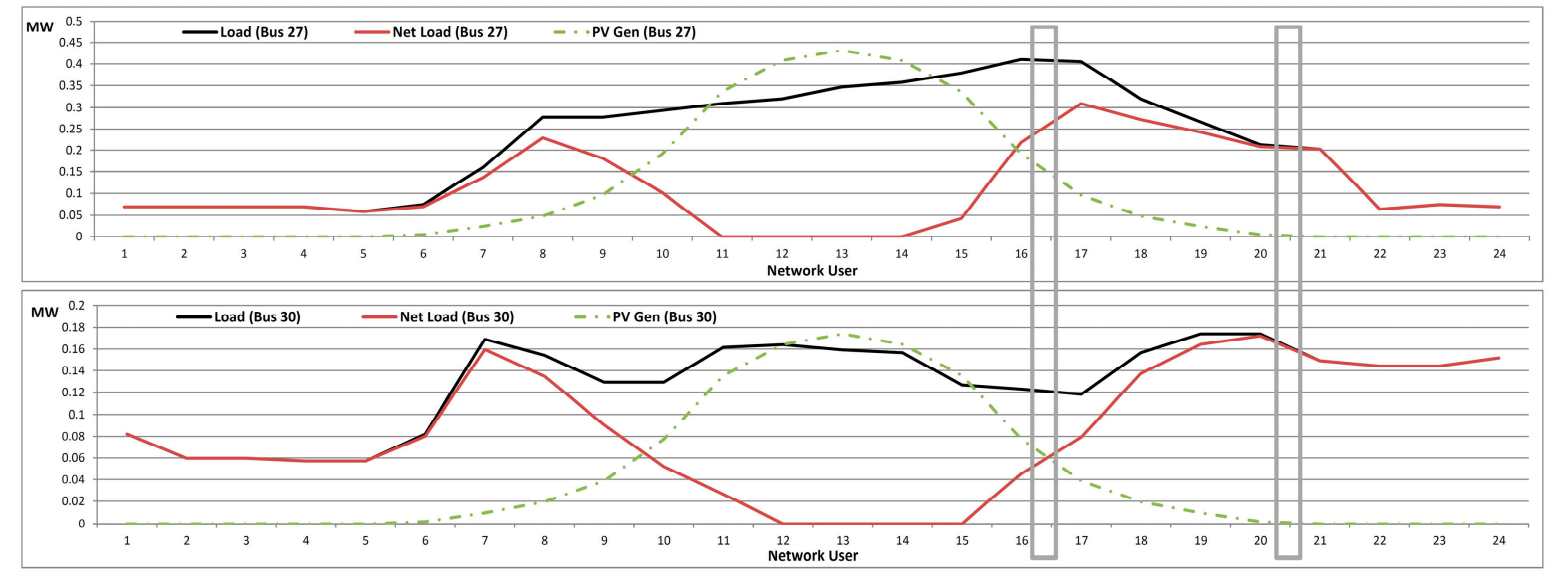

Figure 10. Load reduction through self-generation for network users 27 and 30.

\subsubsection{Efficient Consumer Response}

The traditional tariff design uses flat tariffs, which does not provide any incentives to network users to react to it. Whereas, in the cost-reflective tariff design, the dynamic prices through DLMPs encourages consumers to modify their consumption/injection profiles. DLMPs increase down the feeder due to losses as illustrated in Figure 7, which attracts network users to install generation or reduce their consumption. Besides, the network charges are allocated according to the network's peak, incentivizing consumers to reduce their consumption during those hours.

Furthermore, traditional tariffs are misleading regarding DER investment decisions. Network users are able through DERs to avoid network payments, as shown in Figure 8. However, this was not the case under the cost-reflective tariff design, as only users 22 and 27 were allocated lower payments as their contribution to stressful hours was reduced through their DER installation. Thus, the cost-reflective method guides network users through investments that reduce the system's peak, not individual peaks.

\subsubsection{Recognition of Side-Effects on Consumers}

For the traditional method, as shown in Figure 8, only those who invested in PV were benefitting, and those investment decisions did not impact the rest of the consumers. However, they would be affected in the following period as the tariffs are adjusted to suit the network's new situation. Both the energy and the demand tariff will increase, cross subsidizing passive network users causing them to pay more network costs while active network users pay less [44]. Whereas in the cost-reflective method, during the integration of DERs, DLMPs were reduced noticeably as shown in Figures 6 and 7, benefitting all users. In addition, network charges are allocated based on the contribution to peak hours, with no discrimination between prosumers and consumers. As shown in Figure 9, only prosumers that contributed less to the network stressful hour reduced their payments. The rest of the prosumers were allocated higher payments, mitigating the side-effects generated by traditional tariffs. Moreover, the fairness issue regarding allocation of costs with location aspect consideration was only tackled in the cost reflective method through LMPs. Although some consumers and regulators may disagree whether the location aspect should be considered within the tariff design, it reflects real costs of the network, as well as it indicates nodes that incentivize DER integration. 


\subsection{AHP Evaluation}

First, the performance of each tariff design in each attribute is calculated using the customer payments during PV integration, and results are illustrated in Table 2. For the first attribute, network cost recovery, the cost-reflective method scored 1, indicating full network cost recovery and the $100 \%$ energy scored the least, corresponding to $74 \%$. For the second attribute, deferral of network reinforcements, customer payments were used to calculate the performance of each tariff design. Deferral of network reinforcements is linked to the network's peak hour, thus, payment should be in line with this hypothesis. The MW contribution of each customer during the network's peak hour, is set as a reference. The customer network payment's contribution should follow that reference. The absolute difference in contribution between the reference and each tariff design for each customer is summed and shown in Table 2. The cost-reflective method showed the least difference, while the other tariff designs preformed similarly. As for the third attribute, efficient consumer response, the reference was based on energy payments following DLMPs. DLMPs are efficient economic signals for consumers that consider dynamic prices along with the locational aspect. Again, differences in payments are illustrated in Table 2, where the cost-reflective method scored zero difference, and $100 \%$ demand scored the greatest difference in payments. Finally, for the fourth attribute, recognition of side-effects on consumers, two aspects where considered to affect consumers that have not installed PV: the change in total customer payments of those who did not install PV due to PV integration (which was the case only in the cost-reflective tariff design), and the deficits in cost-recovery that are to be reallocated in the following period (which varied for each tariff design apart from the cost-reflective). As shown in Table 2, 100\% demand scored the least side-effect on consumers, while 100\% energy scored the highest.

Table 2. Performance of each tariff design in each attribute.

\begin{tabular}{ccccc}
\hline \multirow{2}{*}{ Tariff Designs } & \multicolumn{4}{c}{ Design Attributes } \\
\cline { 2 - 5 } & $\mathbf{1}$ & $\mathbf{2}$ & $\mathbf{3}$ & $\mathbf{4}$ \\
\hline 50\% energy-50\% demand & 0.82 & 0.1707 & 241 & 167.7 \\
100\% energy & 0.74 & 0.1753 & 590 & 240 \\
100\% demand & 0.9 & 0.1707 & 725 & 95.4 \\
DLMP + PCNC & 1 & 0.008 & 0 & 127.7 \\
\hline
\end{tabular}

The scores in Table 2 were then used for the pairwise comparison to calculate the relative importance for the tariff designs within each attribute, leading to final scores between 1 and 9 presented in Table 3. The overall AHP evaluation is presented in Figure 11, showing that the cost-reflective method scored the highest, followed by $100 \%$ demand, $50 \%$ energy- $50 \%$ demand, and finally $100 \%$ energy.

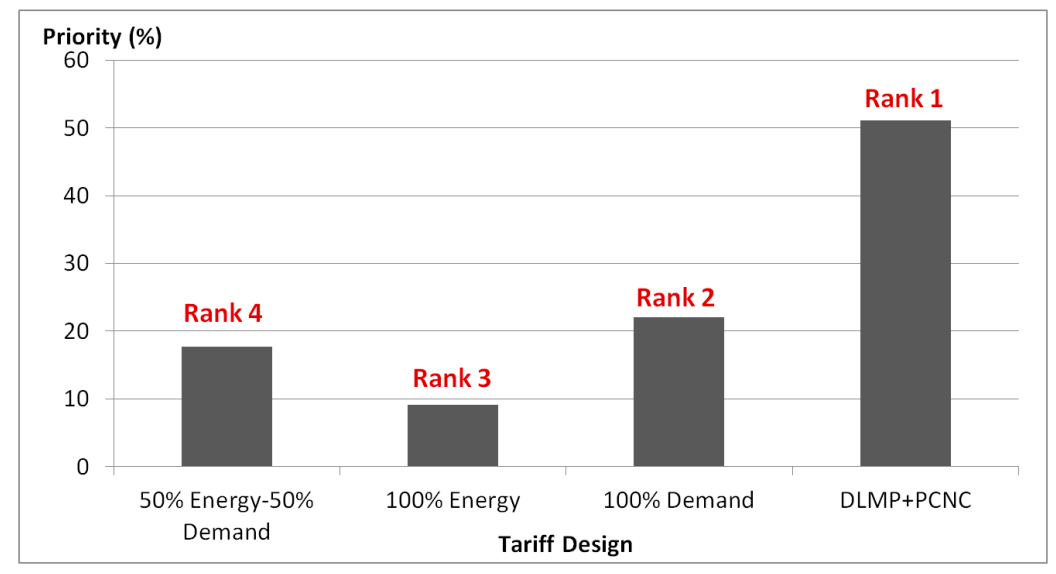

Figure 11. AHP evaluation of tariff design. 
Table 3. Relative performance of each tariff design for each attribute.

\begin{tabular}{ccccc}
\hline \multirow{2}{*}{ Tariff Designs } & \multicolumn{4}{c}{ Design Attributes } \\
\cline { 2 - 5 } & $\mathbf{1}$ & $\mathbf{2}$ & $\mathbf{3}$ & $\mathbf{4}$ \\
\hline 50\% energy-50\% & 3 & 9 & 3 & 3 \\
demand & 4 & 9 & 6 & 5 \\
100\% energy & 2 & 9 & 7 & 1 \\
100\% demand & 1 & 1 & 1 & 2 \\
DLMP + PCNC & 1 &
\end{tabular}

\section{Conclusions}

Traditional tariff designs, based on assuming passive electricity consumers, can no longer serve or deal with the new paradigm of smart distribution networks and active consumers, calling for new tariff designs. Cost-reflective tariffs are required to act as a communicating link between DSOs and network users including consumers, DER owners, or both. The aim is to provide efficient economic signals that reflect the network's status in order to fully benefit from microgrids and hybrid systems in assisting DSOs to maintain the network's security and stability, by mitigating and resolving network problems and voltage deviations. Those tariff designs need to be assessed following an evaluation methodology that includes all desired objectives to guide regulators and policy makers to make their decisions. Through AHP, four tariff designs were evaluated, showing the cost-reflective design is the most capable of achieving the desired outcomes, followed by tariffs based on demand solely, or considering the demand component. In addition, the AHP showed that tariffs that are based solely on energy are leading to inefficient consumer responses and poor network cost recovery. Moreover, dynamic pricing is crucial in tariff design to optimally guide consumers through short- and long-term decisions. The guidance could be more efficient when combined with the locational aspect, as in DLMPs.

The results presented were based on a single day case study, which may differ if a different day with other seasonal conditions, or a year-long time frame with weekly and seasonal variations in demand and PV output were considered. The objective was to present how the proposed evaluation method could be used as a tool to compare different tariff designs. Finally, the AHP results presented are based on equal weight of each attribute, which could vary between regulators according to their preferences and contextual frameworks.

Acknowledgments: The work of Ibtihal Abdelmotteleb is funded through the European Commission's Joint Doctorate on Sustainable Energy Technologies and Strategies (SETS).

Author Contributions: Ibtihal Abdelmotteleb and Tomás Gómez proposed the framework and participated in the preparation of the manuscript. Javier Reneses collaborated in developing the research design and assessment framework. Ibtihal Abdelmotteleb wrote the paper and improved it further with the feedback from Tomás Gómez and Javier Reneses.

Conflicts of Interest: The authors declare no conflict of interest.

\section{References}

1. Ou, T.-C. A novel unsymmetrical faults analysis for microgrid distribution systems. Int. J. Electr. Power Energy Syst. 2012, 43, 1017-1024. [CrossRef]

2. Ou, T.-C. Ground fault current analysis with a direct building algorithm for microgrid distribution. Int. J. Electr. Power Energy Syst. 2013, 53, 867-875. [CrossRef]

3. Kim, J.; Kim, S.W.; Jin, Y.G.; Park, J.-K.; Yoon, Y.T. Optimal coordinated management of a plug-in electric vehicle charging station under a flexible penalty contract for voltage security. Energies 2016, 9, 538. [CrossRef]

4. Hong, C.-M.; Ou, T.-C.; Lu, K.-H. Development of intelligent MPPT (maximum power point tracking) control for a grid-connected hybrid power generation system. Energy 2013, 50, 270-279. [CrossRef]

5. Ilić, M.D.; Yoon, Y.T.; Zobian, A.; Paravalos, M.E. Toward regional transmission provision and its pricing in New England. Util. Policy 1997, 6, 245-256. [CrossRef] 
6. Li, F.; Padhy, N.P.; Wang, J.; Kuri, B. Cost-benefit reflective distribution charging methodology. IEEE Trans. Power Syst. 2008, 23, 58-64. [CrossRef]

7. Sotkiewicz, P.M.; Vignolo, J.M. Allocation of fixed costs in distribution networks with distributed generation. IEEE Trans. Power Syst. 2006, 21, 639-652. [CrossRef]

8. Mekonnen, M.T.; De Jonghe, C.; Rawn, B.; Van Hertem, D.; Belmans, R. Power flow control and its effect on flow-based transmission cost allocation. In European Energy Market (EEM), Proceeding of the 2013 10th International Conference on the, Stockholm, Sweden, 27-31 May 2013; IEEE: Piscataway, NJ, USA, 2013; pp. 1-8.

9. Rudnick, H.; Palma, R.; Fernandez, J.E. Marginal pricing and supplement cost allocation in transmission open access. IEEE Trans. Power Syst. 1995, 10, 1125-1132. [CrossRef]

10. González, A.; Gomez, T. Use of system tariffs for distributed generators. In Proceedings of the 16th Power Systems Computation Conference, Glasgow, Scotland, 14-18 July 2008.

11. Rubio-Oderiz, F.J.; Perez-Arriaga, I.J. Marginal pricing of transmission services: A comparative analysis of network cost allocation methods. IEEE Trans. Power Syst. 2000, 15, 448-454. [CrossRef]

12. Gu, C.; Li, F. Long-run marginal cost pricing based on analytical method for revenue reconciliation. IEEE Trans. Power Syst. 2011, 26, 103-110. [CrossRef]

13. Li, F. Long-run marginal cost pricing based on network spare capacity. IEEE Trans. Power Syst. 2007, 22, 885-886. [CrossRef]

14. Gu, C.; Li, F.; He, Y. Enhanced long-run incremental cost pricing considering the impact of network contingencies. IEEE Trans. Power Syst. 2012, 27, 344-352. [CrossRef]

15. Li, F.; Tolley, D.; Padhy, N.P.; Wang, J. Framework for assessing the economic efficiencies of long-run network pricing models. IEEE Trans. Power Syst. 2009, 24, 1641-1648. [CrossRef]

16. Perez-Arriaga, I.J.; Rubio, F.J.; Puerta, J.F.; Arceluz, J.; Marin, J. Marginal pricing of transmission services: An analysis of cost recovery. IEEE Trans. Power Syst. 1995, 10, 546-553. [CrossRef]

17. Reneses, J.; Rodríguez Ortega, M.P. Distribution pricing: Theoretical principles and practical approaches. IET Gener. Transm. Distrib. 2014, 8, 1645-1655. [CrossRef]

18. Akinbode, O.W. A Distribution-Class Locational Marginal Price (DLMP) Index for Enhanced Distribution Systems. Master's Thesis, Arizona State University, Arizona, AZ, USA, 2013.

19. Siano, P.; Sarno, D. Assessing the benefits of residential demand response in a real time distribution energy market. Appl. Energy 2016, 161, 533-551. [CrossRef]

20. Sotkiewicz, P.M. Nodal pricing and MW-mile methods for distribution: Have we uncovered missing markets or elements for wholesale power markets? In Proceedings of the Harvard Electricity Policy Group 42nd Plenary Session, La Jolla, CA, USA, 2 March 2006.

21. Ignacio, P.-A.; Ashwini, B. A Framework for Redesigning Distribution Network Use of System Charges under High peneTration of Distributed Energy Resources: New Principles for New Problems; MIT Center for Energy and Environmental Policy Research: Cambridge, MA, USA, 2014.

22. Rodríguez Ortega, M.P.; Pérez-Arriaga, J.I.; Abbad, J.R.; González, J.P. Distribution network tariffs: A closed question? Energy Policy 2008, 36, 1712-1725. [CrossRef]

23. Biggar, D.R.; Hesamzadeh, M.R. The smart grid and efficient pricing of distribution networks. In The Economics of Electricity Markets; Darryl, R.B., Mohammad, R.H., Eds.; Wiley-IEEE Press: Hoboken, NJ, USA, 2014.

24. Wang, Y.; Li, L. Critical peak electricity pricing for sustainable manufacturing: Modeling and case studies. Appl. Energy 2016, 175, 40-53. [CrossRef]

25. Granell, R.; Axon, C.J.; Wallom, D.C.H. Predicting winning and losing businesses when changing electricity tariffs. Appl. Energy 2014, 133, 298-307. [CrossRef]

26. Jeong, M.-G.; Moon, S.-I.; Hwang, P.-I. Indirect load control for energy storage systems using incentive pricing under time-of-use tariff. Energies 2016, 9, 558. [CrossRef]

27. Kim, H.; Heo, J.-H.; Park, J.-Y.; Yoon, Y.T. Impact of battery energy storage system operation strategy on power system: An urban railway load case under a time-of-use tariff. Energies 2017, 10, 68. [CrossRef]

28. Parra, D.; Patel, M.K. Effect of tariffs on the performance and economic benefits of PV-coupled battery systems. Appl. Energy 2016, 164, 175-187. [CrossRef]

29. Jargstorf, J.; De Jonghe, C.; Belmans, R. Assessing the reflectivity of residential grid tariffs for a user reaction through photovoltaics and battery storage. Sustain. Energy Grids Netw. 2015, 1, 85-98. [CrossRef] 
30. De Sa Ferreira, R.; Barroso, L.A.; Rochinha Lino, P.; Carvalho, M.M.; Valenzuela, P. Time-of-use tariff design under uncertainty in price-elasticities of electricity demand: A stochastic optimization approach. IEEE Trans. Smart Grid 2013, 4, 2285-2295. [CrossRef]

31. Abdelmotteleb, I.; Roman, T.G.S.; Reneses, J. Distribution network cost allocation using a locational and temporal cost reflective methodology. In Proceedings of the 19th Power Systems Computation Conference (PSCC 2016), Genoa, Italy, 20-24 June 2016.

32. Hobman, E.V.; Frederiks, E.R.; Stenner, K.; Meikle, S. Uptake and usage of cost-reflective electricity pricing: Insights from psychology and behavioural economics. Renew. Sustain. Energy Rev. 2016, 57, 455-467. [CrossRef]

33. Swami, R. Social welfare maximization in deregulated power. Int. J. Power Syst. Oper. Energy Manag. 2012, 1, 2231-4407.

34. Reneses, J.; Rodriguez, M.P.; Pérez-Arriaga, J.I. Chapter 8: Electricity tariffs. In Regulation of the Power Sector; Pérez-Arriaga, I.J., Ed.; Springer: Berlin, Germany, 2013.

35. Jones, D.N.; Mann, P.C. The fairness criterion in public utility regulation: Does fairness still matter? J. Econ. Issues 2001, 35, 153-172. [CrossRef]

36. Saaty, T.L. Decision making with the analytic hierarchy process. Int. J. Serv. Sci. 2008, 1, 83-98. [CrossRef]

37. Handfield, R.; Walton, S.V.; Sroufe, R.; Melnyk, S.A. Applying environmental criteria to supplier assessment: A study in the application of the analytical hierarchy process. Eur. J. Oper. Res. 2002, 141, 70-87. [CrossRef]

38. Zimmerman, R.D.; Murillo-Sánchez, C.E.; Thomas, R.J. MATPOWER: Steady-State Operations, Planning, and Analysis Tools for Power Systems Research and Education. IEEE Trans. Power Syst. 2011, 26, 12-19. [CrossRef]

39. Distribution Test Feeder Working Group IEEE Distribution Test Feeders. Available online: http:/ / ewh.ieee. org/soc/pes/dsacom/testfeeders/ (accessed on 3 March 2015).

40. Mithulananthan, N.; Saha, T. Power and Energy Research Group: Test System Report; School of Information Technology and Electrical Engineering, The University of Queensland: Brisbane, Australia, 2011.

41. OMIE. Available online: http:/ / www.omie.es/ (accessed on 15 May 2015).

42. Pflugradt, N.; Teuscher, J.; Platzer, B.; Schufft, W. Analysing low-voltage grids using a behaviour based load profile generator. In Proceedings of the International Conference on Renewable Energies and Power Quality, Bilbao, Spain, 20-22 March 2013.

43. Gómez, T.; Mateo, C.; Sánchez, Á.; Frías, P.; Cossent, R. Reference network models: A computational tool for planning and designing large-scale smart electricity distribution grids. In High Performance Computing in Power and Energy Systems; Siddhartha Kumar, K., Gupta, A., Eds.; Springer Berlin Heidelberg: Berlin, Germany, 2013; pp. 247-279.

44. Eid, C.; Reneses Guillén, J.; Frías Marín, P.; Hakvoort, R. The economic effect of electricity net-metering with solar PV: Consequences for network cost recovery, cross subsidies and policy objectives. Energy Policy 2014, 75, 244-254. [CrossRef]

(C) 2017 by the authors. Licensee MDPI, Basel, Switzerland. This article is an open access article distributed under the terms and conditions of the Creative Commons Attribution (CC BY) license (http:// creativecommons.org/licenses/by/4.0/). 